\title{
A EDUCAÇÃO DO CORPO EM AMBIENTES EDUCACIONAIS*
}

\author{
Ari LAZZAROTTI FiLho** \\ LílIAN BRANDÃo BANDEIRA*** \\ Antonio Chadud Jorge****
}

\section{RESUMO}

Este trabalho apresenta as principais questões oriundas de pesquisa que objetivou investigar, em perspectiva comparada, os cuidados com o corpo e as técnicas corporais na educação escolar de crianças e jovens. Procuramos correlacionar aspectos de conteúdos e metodologias do ensino de Educação Física com as disciplinas Ciências e Ensino Religioso, assim como do esporte escolar e sua presença nas aulas de Educação Física. A pesquisa foi realizada com alunos e professores da segunda fase do Ensino Fundamental, em escola pública de Goiânia, onde percebemos a educação do corpo sustentada por uma concepção biológica, com valorização da disciplina Ciências. O esporte escolar mantém, através do sistema esportivo, o modelo de manifestação e expressão na escola por intermédio das competições, da formação dos ídolos, da racionalização, do treinamento e do desenvolvimento dos seus valores. Ao final, constatamos a necessidade de entender a educação do corpo de forma multidisciplinar e de ampliar o foco de ensino do esporte na escola.

PALAVRAS-CHAVE: educação do corpo - escola - educação física - esporte escolar

\section{INTRODUÇÃO}

educação do corpo em ambientes educacionais tem sido a centra-
lidade das nossas discussões e preocupações que culminaram com o desenvolvimento desta pesquisa de forma integrada entre pesquisadores de quatro instituições do ensino superior da Educação Física do Brasil. Tal enfoque se sustenta em lacuna identificada nas pesquisas

* Pesquisa financiada em 2003 e 2004 pelo Programa de Licenciatura da UFG.

** Professor mestre da Faculdade de Educação Física da Universidade Federal de Goiás e sócio pesquisador do CBCE.

*** Aluna da Especialização em Metodologia do Ensino Fundamental do Cepae/UFG e licenciada em Educação Física pela FEF/UFG.

**** Licenciado em Educação Física pela FEF/UFG e professor da Rede Estadual de Ensino de Goiás. 
atuais. Por um lado, a falta de investigação empírica sistemática e contínua nas escolas e, por outro, a possibilidade de se pensar a educação do corpo e seus dispositivos pedagógicos/disciplinares como projeto. Estas lacunas estão articuladas em uma questão mais ampla, que tentamos responder: É o corpo e suas expressões uma categoria por meio da qual se pode compreender o tempo presente?

Embora diga respeito diretamente à Educação Física, está presente também em outros espaços e tempos escolares, uma vez que a multivocalidade do corpo autoriza - e mesmo exige - sua presença em disciplinas do currículo escolar. Da mesma forma, nos ambientes externos à sala de aula ou às quadras e pátios, o corpo continua sendo um vetor importante da educação, seja nas práticas alimentares/nutricionais, hábitos de higiene ou nos procedimentos de castigo.

A pesquisa teve caráter exploratório com o intuito de trabalhar em perspectiva comparada, em quatro diferentes cidades brasileiras, articulada por pesquisadores em rede, interessados na compreensão das expressões do corpo e sua educação na escola e na construção teórico-metodológica de instrumentos que possam ajudar a consolidar uma prática crítica de investigação (e, indiretamente, de intervenção) na Educação Física Escolar. Consideramos, nesse sentido, que a educação do corpo contém uma universalidade e esta só pode ser captada nas múltiplas singularidades que se colocam e recolocam em cada escolacampo investigada.

O objetivo desta pesquisa foi investigar os cuidados com o corpo e as técnicas corporais na educação escolar de crianças e jovens, correlacionando aspectos de conteúdos e metodologias do ensino de Educação Física com as disciplinas Ciências e Ensino Religioso, assim como do esporte escolar e sua presença nas aulas de Educação Física.

Neste trabalho, constituímos uma análise preliminar, ${ }^{1}$ levantando categorias descritivas/explicativas da educação do corpo em uma escola da Rede Estadual de Educação da cidade de Goiânia (GO). Os instrumentos utilizados para a coleta de dados foram entrevistas semiestruturadas com 14 alunos e com os professores de Educação Física, Ciências e Ensino Religioso que ministram aulas na segunda fase do Ensino Fundamental.

Também foram realizadas entrevistas semi-estruturadas com quatro alunos/atletas participantes da equipe de treinamento de futsal, uma entrevista semi-estruturada com professor/treinador que ministra 
o treinamento desportivo de futsal e, por último, uma entrevista semiestruturada com o coordenador geral dos JEEGO's.

Foram utilizados protocolos para observação de aulas e de treinamentos e protocolo para observação de jogos, que nos permitiram a construção de relatórios diários. Os elementos norteadores desses protocolos buscavam contemplar rotinas e rituais das aulas, formas de organização e condução da aula, conteúdos e metodologias trabalhados pelo professor, questões referentes a preconceito, higiene e saúde, assim como perceber diálogos de alunos, interferências de funcionários e/ou de outros sujeitos nas aulas, caracterização da vestimenta dos alunos, entre outros.

A partir do cruzamento entre as categorias surgidas da realidade e do nosso objeto, abordaremos três aspectos relevantes referentes aos conteúdos e metodologias da educação do corpo, às manifestações do corpo nas aulas de Educação Física, Ensino Religioso e Ciências e às manifestações do esporte escolar.

\section{CONTEÚDOS E METODOLOGIAS DA EDUCAÇÃO DO CORPO}

A observação das aulas de Educação Física foi realizada durante o segundo semestre de 2003 (agosto - dezembro) em uma turma de $5^{\text {a }}$ Série e em uma turma de $8^{\text {a }}$ Série do Ensino Fundamental. Como a escola se organiza a partir de um calendário anual dividido em dois semestres, optamos em observar todas as aulas ministradas durante $o$ $2^{0}$ semestre. Tal procedimento nos trouxe um panorama de como se estrutura e se operacionaliza as aulas de Educação Física. As aulas de Educação Religiosa e Ciências não tiveram o mesmo tratamento, pois só conseguimos nos organizar para sua observação na segunda metade do $2^{\circ}$ semestre.

O primeiro dado a nos chamar a atenção foi a dinâmica escolar que, diferentemente da nossa pesquisa, tinha um cronograma preestabelecido. Percebemos que o horário das aulas nessas turmas oscilava freqüentemente devido à constante mudança de horários. Essa oscilação acontecia de acordo com as necessidades da própria escola e com a sua dinâmica.

Durante o segundo semestre de 2003, 49 aulas de Educação Física foram observadas e sistematizadas, porém somente 19 foram efetiva- 
mente ministradas, e a carga horária dessa disciplina corresponde a duas aulas semanais por turma de 50 minutos cada. Diante disso, podemos perceber que as aulas de Educação Física não ocorrem por inúmeros motivos: modificação do horário de aulas, datas comemorativas, falta de professores da área e de outras áreas, jogos escolares, paralisações e outras atividades do âmbito escolar (paradas coletivas, entrega de boletins escolares e reunião de pais e professores).

Foram observadas também aulas de Ciências ${ }^{2}$ e Ensino Religioso $^{3}$ numa turma de $7^{\text {a }}$ Série. Notamos que das 12 aulas de Ciências previstas e por nós observadas, sete foram ministradas e das quatro aulas de Ensino Religioso, apenas uma foi ministrada.

As aulas dessas disciplinas também sofrem interferência de todos os fatores supracitados, no entanto, observamos que o conteúdo planejado é ensinado aos alunos através de uma seqüência lógica, de continuidade e de organização. As observações nos apontam um saber específico sendo ensinado e que se efetiva na prática, principalmente relacionado com a disciplina Ciências. Isso é perceptível nas aulas observadas, nas entrevistas realizadas com as professoras de Ciências e Ensino Religioso e com os alunos. Para os alunos, a importância da disciplina Ciências é bastante clara e definida.

Observamos ainda que, tanto na disciplina Ensino Religioso como em Ciências, há uma variedade de recursos didático-pedagógicos utilizados pelas professoras: figuras, vídeos, textos, livros didáticos e pára-didáticos, desenhos e escritos explicativos no quadro-negro. Esses recursos estão disponíveis ou são adquiridos na escola pela iniciativa das professoras. Outra observação refere-se à nítida intervenção das professoras que expõem conteúdos e saberes aos alunos, não limitando suas aulas ao "deixar fazer" e ainda consideram o conhecimento que os alunos já possuem a respeito do conteúdo ministrado. Talvez estas observações possam nos auxiliar no entendimento de existência de uma hierarquia entre as disciplinas do currículo escolar em que a Educação Física aparece "marginalizada" em relação às demais. ${ }^{4}$

Em relação ao conteúdo e à metodologia adotados nas aulas de Educação Física, observamos que há uma variedade e complexidade de elementos e aspectos que tangem a educação do corpo e as técnicas corporais no âmbito escolar. Assim, diante da dificuldade de materialização de propostas (críticas ou não) da Educação Física Escolar, nos deparamos com ranços e avanços da prática pedagógica dos professores 
que ministram essas aulas. Entre as maiores dificuldades encontradas pelos professores em ministrar suas aulas estão a aceitação dos alunos, a falta de materiais didático-pedagógicos, a falta de infra-estrutura da escola e a deficiência na formação dos professores.

Em contrapartida, percebemos tentativas pertinentes desses professores para modificar a visão dos alunos e de outros professores da escola em relação às aulas de Educação Física (conteúdo e metodologia), buscando legitimar este campo do conhecimento.

Mesmo com as tentativas dos professores, o conteúdo das aulas de Educação Física, em sua maioria, perpassava o âmbito "esportivo" e recreativo, e em muitas aulas presenciamos a divisão de turmas em meninos - jogando futebol na quadra - e meninas - "treinando" queimada embaixo das árvores, em virtude dos Jogos Escolares Estaduais.

Apesar destes enfoques, a intervenção das professoras configuravase de forma bastante limitada, uma vez que o esporte enquanto conteúdo não era ensinado e transmitido aos alunos, pois o seu ensino demonstrava a ausência de planejamento e de seqüência pedagógica coerente.

Diante dos conteúdos e metodologias abordados na disciplina Educação Física, percebemos também dicotomias entre aulas teóricas e aulas práticas, aulas dentro de sala e aulas fora de sala presentes nas entrevistas das professoras e em diálogos durante as aulas. Às vezes, essas dicotomias aparecem como tentativa de as professoras legitimarem a Educação Física, a fim de que os alunos entendam que este campo do conhecimento possui conteúdos a serem ministrados.

Assim, notamos que essas professoras mostram-se conscientes da amplitude de conhecimentos que a Educação Física deve tratar na escola. Entretanto, as aulas ministradas dentro de sala são consideradas como castigo.

No que tange à Educação Física dentro da escola pesquisada, notamos que os problemas de falta de legitimidade de ensino dos conteúdos e de procedimentos metodológicos que auxiliem no processo ensino-aprendizagem perpassam necessariamente por um projeto. Segundo as professoras, este projeto não existe, o que dificulta o planejamento das aulas e o trabalho pedagógico com os alunos.

Assim, percebemos as inúmeras dificuldades de se legitimar o conteúdo da Educação Física na escola e de tratá-lo em toda a sua amplitude. Entretanto, as professoras entendem e tentam minimamente buscar formas de materializar uma proposta de aula. 
Além disso, a Educação Física, enquanto campo do conhecimento, teve, ao longo de sua trajetória dentro e fora da escola, forte influência médica, eugênica e esportiva. Talvez estes aspectos também devam ser considerados na análise dos conteúdos e metodologias da Educação Física Escolar que continuam vigorando nos intramuros escolares.

\section{AS MANIFESTAÇÕES DO CORPO NAS AULAS DE CIÊNCIAS, EDUCAÇÃO FÍSICA E ENSINO RELIGIOSO}

$\mathrm{Na}$ tentativa de ampliar nosso entendimento acerca da educação do corpo na escola, buscamos articular os desdobramentos deste objeto nas disciplinas Ciências, Educação Física e Ensino Religioso.

O corpo tem se apresentado como um dos mais complexos e instigantes fenômenos e nos possibilita a compreensão da realidade na qual estamos inseridos. Neste tocante estão as relações homem-homem, homem-natureza e homem-sociedade que se configuram em elementos chaves para entendermos as formas como a escola educa o corpo. No corpo, no movimento humano e em todo o universo das práticas e técnicas corporais estão intrínsecos valores sociais, culturais, políticos e econômicos do momento histórico que perpassa a trajetória do homem em sociedade.

Como espaço privilegiado para a formação humana e aquisição de conhecimentos sistematizados, a escola desenvolveu a noção de educação do corpo como elemento estratégico de sua intervenção educativa, trazendo uma predominância de concepção de corpo restrita aos aspectos biológicos, sinalizando a hegemonia do conceito cartesiano, além da exacerbada preocupação com a saúde e a aparência, visando ao alcance da "boa forma". É neste contexto também que se desenvolve a educação intelectual separada de uma educação corporal, justapondoas. Assim,

a educação corporal vai pautar-se pela idéia, culturalmente cristalizada, de superioridade da esfera mental ou intelectual - a razão como identificadora da dimensão essencial e definidora do ser humano. O corpo deve servir. O sujeito é sempre a razão, ele (o corpo) é sempre objeto; a emancipação é identificada com a racionalidade da qual o corpo estava por definição, excluído (BRACHT, 1999, p. 69). 
Dessa forma, a razão torna-se essência do homem e o corpo mero objeto a ser conhecido e investigado. Outro elemento estratégico referese aos mecanismos de controle através de técnicas disciplinares, visando à contenção de gestos e atitudes, educando o corpo de acordo com valores socialmente aceitos. "O corpo é, em primeiro momento, o objeto e a vítima preferencial da civilização, cuja história pode ser lida nos anais do crescente processo de controle daquele, e pelo desenvolvimento de técnicas que medeiam este domínio" (VAZ, 1999, p. 91).

A escola, enquanto instituição social responsável pela produção e sistematização do conhecimento historicamente produzido pelo homem, configura-se num fértil espaço para se refletir a educação do corpo e conseqüentemente os mecanismos utilizados pela classe dominante para se manter no poder. Como parte importante do processo de disseminação cultural, a escola ensina e reproduz grande parte das técnicas corporais ${ }^{5}$ de determinado momento histórico, várias delas privilegiadas nas aulas de Educação Física. As técnicas disciplinares ${ }^{6}$ estão

relacionadas à arquitetura da escola, ao planejamento dos espaços de deslocamento, às proibições e interditos. Nesse quadro, estar atento à dinâmica dos castigos é um exercício muito importante. Há uma série de castigos nos ambientes educacionais, muitos deles relacionados a dores e privações corporais (VAZ, 2002, p. 95).

Essas técnicas se materializam no âmbito escolar com o intuito de docilizar o corpo através do controle de ações, adestramento de gestos, manipulação de desejos, a fim de mantê-lo submisso à ordem vigente, não manifestando qualquer atitude que fuja dos padrões de comportamento denominados corretos na sociedade. Com isso, o corpo configura-se num palco de contradições que refletem as condições concretas de existência e também numa possibilidade de enfrentamento e luta contra as regras dominantes em nossa sociedade.

No bojo da discussão que permeia a disciplina na escola, os castigos corporais e as regras para sair de sala (ir ao banheiro e beber água) são algumas estratégias concretas utilizadas pelos professores e demais funcionários do nosso lócus de pesquisa para o disciplinamento corporal.

Ponto que merece destaque são as relações de gênero que se estabelecem nas aulas de uma forma geral. Durante a observação das aulas, percebemos uma divisão "espontânea" de meninos e meninas, que se 
sentavam em lugares extremos da sala e somente alguns se misturavam com colegas de outro sexo. Isto ficou bastante perceptível nas aulas de Educação Física que, em sua maioria, eram realizadas na quadra (lugar onde os meninos jogavam futebol) e num espaço de terra vermelha embaixo das árvores (local onde as meninas jogavam vôlei e/ou queimada).

A educação do corpo no ambiente escolar não é responsabilidade exclusiva da Educação Física, mas perpassa por outras disciplinas como Ciências e Ensino Religioso. Vaz (2002) afirma que, embora essas questões digam respeito diretamente à Educação Física, estão presentes também em outros espaços e tempos escolares. Nesse sentido, percebemos que o conteúdo da disciplina Ciências perpassa o estudo do corpo privilegiando os aspectos biológicos. Nas aulas assistidas, o conteúdo abordado foi o sistema reprodutor masculino e feminino e

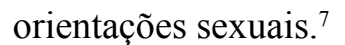

É válido ressaltar uma fala da professora de ciências quando afirma que o corpo é trabalhado dentro de uma perspectiva biológica, e por mais que entenda que o corpo não é só biológico não tem conseguido tratá-lo diferentemente.

Na disciplina Ensino Religioso, os conteúdos trabalhados são correlacionados aos valores humanos, e um dos temas já abordados, segundo a professora, foi a estética.

Já falei sobre a questão da beleza, essa questão que tá muito em evidência, a questão da estética, da anorexia, da bulimia [...] Também mostrei a questão da estética mesmo, essa busca alucinada de transformar o corpo, quais as conseqüências né, o que isso pode causar, se tem algum prejuízo, a prática de esportes (Professora de Ensino Religioso).

Outros conteúdos trabalhados pela professora relacionam-se à higiene e a orientações sexuais que, segundo ela, não são norteados por uma religião específica, tendo Deus como princípio básico. Quanto ao seu entendimento do que venha a ser corpo, esta apresentou uma concepção de soma do externo com o interno.

Para os alunos entrevistados, o conhecimento do corpo que eles possuem é oriundo da disciplina Ciências. A Educação Física não é reconhecida por esses alunos como importante e responsável pelos seus conhecimentos sobre o corpo. 
Na disciplina Ciências, podemos perceber um predomínio do ensino do corpo de forma fragmentada, restrito aos aspectos biológicos e desvinculado de um contexto social e histórico. Neste aspecto,

é importante entender o corpo como resultado provisório de diversas pedagogias que o conformam em determinadas épocas e lugares; que ele é marcado e distinguido muito mais pela cultura do que por uma presumível essência natural; que adquire diferentes sentidos no momento em que é investido por um poder regulador que o ajusta em seus menores detalhes, impondo limitações, autorizações e obrigações, para além de sua condição fisiológica (FRAGA, 2001, p. 63).

Esta forma de as ciências biológicas se apropriarem do corpo e buscarem difundi-la na escola tem profundos vínculos com a concepção de corpo presente na modernidade e aponta para uma ruptura do homem com a natureza, sendo esta objeto a ser conhecido e dominado pela razão humana. Assim, o homem torna-se superior à natureza e esta passa a ser exterior a ele, não mais pertencente ao mesmo numa relação mimética.

$\mathrm{Um}$ aspecto que podemos levantar refere-se ao

modo fragmentário que se caracteriza não só a ciência, mas toda a cultura ocidental, onde as coisas são tratadas como divididas e desconectadas [...] leva a um reforço ao individualismo e à autopreservação do ego de forma exacerbada, além de certo grau de neurose no próprio indivíduo que vê a si mesmo como fragmentado (SILVA, 2001, p. 108).

Outros vetores passíveis de interferência das pedagogias do corpo estão nas relações de preconceito. Durante as aulas assistidas, as relações de preconceito estiveram bastante interligadas com a estética corporal, demonstrando o quanto o padrão de beleza socialmente estabelecido está presente nas relações entre os alunos.

Os padrões de corpo hegemônicos, submetidos à racionalidade e ao avanço científico, ${ }^{8}$ apareceram reproduzidos no discurso dos alunos. Esta situação ficou perceptível em conversas de alguns alunos durante as aulas de Educação Física em que comentavam a beleza ou a fealdade de colegas de classe e que, por alguns momentos, apareciam dotadas de preconceitos quanto à estatura, cor de pele, peso corporal e estrutura facial.

Diante dos dados coletados na pesquisa, podemos notar que os padrões corporais impostos pela mídia aparecem com veemência nas 
atitudes e discursos dos alunos e quase sempre estão relacionados a artistas de televisão que submeteram-se a intervenções cirúrgicas e químicas para atingir o padrão de corpo exigido como condição para o sucesso e o assédio que movimentará o mercado consumidor.

No bojo da sociedade do capital, o corpo tem caráter de mercadoria, havendo também uma universalização de padrões. Sob esta tônica

a comunicação torna-se o elo mais poderoso do processo de globalização, identifica-se o surgimento de uma nova utopia e substituição àquelas perdidas ou ainda inacessíveis: uma utopia centrada no corpo, na saúde em aliança para a beleza (SILVA, 2001, p. 54).

Uma faceta do capitalismo perante o homem se manifesta na incessante busca pela saúde e pela beleza, traduzindo-se no individualismo e numa opção pelo privado que culminará numa ênfase narcisista. Assim, há uma perda do eu enquanto coletivo e social.

A busca do belo e perfeito, segundo Codo, nada mais é que a busca pela reapropriação de si mesmo, um protesto contra a alienação do trabalho. Para o autor, a corpolatria complementa a idéia de corpo-mercadoria difundido pelo sistema capitalista (CODO; SENNE, 1985).

Para Werneck (1997), a ênfase biológica e a dicotômica que fragmentam a totalidade humana ampliam as possibilidades de manobras sobre o corpo pelo jogo de poder, histórica e socialmente constituído na educação física. Assim, o esclarecimento sobre a constituição do imaginário social em relação às questões inerentes ao corpo constitui-se uma das estratégias capazes de libertar o homem das armadilhas impostas pela alienação, tensionando os valores hegemônicos para que haja emancipação.

No corpo, no movimento humano e em todo o universo das práticas corporais estão intrínsecos os valores sociais, culturais, políticos e econômicos, portanto, não devemos restringi-los ao âmbito biológico (de domínio e controle do corpo, submetendo-o a uma racionalidade restrita), mas ampliá-los na nossa prática pedagógica. A restrição ao âmbito biológico leva a uma biologização e naturalização dos problemas sociais como os preconceitos raciais, preconceitos em relação à opção sexual, fracasso escolar e exclusão social. 


\section{AS MANIFESTAÇÕES DO ESPORTE ESCOLAR}

A educação do corpo através do esporte escolar é um dos principais vetores presentes na escola. De um lado, o esporte escolar aparece como conteúdo hegemônico presente nas aulas de educação física; de outro, aparece nos projetos extracurriculares mantidos pela Secretaria Estadual de Educação e pelo Ministério dos Esportes via Projeto Segundo Tempo. Estas duas principais manifestações do esporte escolar culminam com os Jogos Estudantis de Goiás.

Reconhecidos como importante fator da educação do corpo, observamos os projetos de treinamento e uma etapa dos JIEGO's, na qual acompanhamos uma equipe de futsal masculina nos processos de treinamento e participação nos JEEGO's.

Foram observadas 19 aulas das quais $84,2 \%$ tiveram como tema central o esporte - mais precisamente futebol e vôlei; do restante, 10,5\% foram destinados à queimada como conteúdo principal - porém trabalhado em forma de treinamento; e 5,3\%, jogos alternativos.

Dentro das aulas em que o esporte foi trabalhado, ele apresentou-se de várias maneiras, a mais comum como recreação. Em quase todas as aulas isto aconteceu, ora parte do tempo da aula, ora em tempo integral. Outras maneiras recorrentes foram a sua relação com a "saúde" e como esporte de rendimento, fazendo treinamentos, organizando competições, tudo isso dentro do espaço das aulas de Educação Física.

Em nossa pesquisa, conseguimos observar como acontecem determinadas manifestações desse fenômeno dentro da escola, algumas muito comuns em aulas de Educação Física, como a supremacia do "jogar bola", melhor dizendo, jogar futebol. Foi possível observar que a maioria dos alunos e alunas entende a aula de Educação Física só para jogar futebol, de preferência sem nenhuma interferência, como afirma uma professora.

então eu tô vendo dificuldade nisso, eles não sabem o que é [...] a educação física. É só uma bola? Tem que ser do jeito que eles querem, você não pode nem administrar a aula, tem que ser do jeito que eles querem, eles não sabem que os conteúdos têm que ser ensinados. Por que que tem que ser, eles acham que tem que ser só lá fora, tem que ser só a bola, tem que ser só recreação, então eu vejo muita dificuldade nisso (Professora de Educação Física 2). 
O depoimento da professora reflete um dos problemas em se trabalhar o esporte de qualquer maneira nas aulas de Educação Física: os alunos passam a não compreender o esporte enquanto conteúdo/conhecimento a ser apreendido, mas sim enquanto jogo, reproduzindo suas brincadeiras de rua ou reproduzindo o esporte visto pela televisão.

Entretanto, para que o modelo esportivo de rendimento possa ser superado dentro da escola, é preciso que os professores não o reforcem. Em nossa pesquisa, identificamos algumas contradições em que as professoras se diziam contra o modelo de esporte rendimento.

Esporte geralmente eu trabalho, em questão do esporte com os alunos, não gosto de trabalhar competitividade, não trabalho, assim, eu trabalho mais o esporte em questão de união de trabalho em grupo pra eles ficarem assim mais civilizados, não é só competir, procuro assim enfatizar pra eles que muitas vezes a gente num deve só ganhar, deve também perder mas saber como perder (Professora 2).

Nos relatórios foi identificado o inverso. Além de promover competições sustentadas no modelo do esporte rendimento, foram utilizadas várias aulas de Educação Física para o treinamento da equipe de queimada, ${ }^{9}$ deixando assim o conteúdo de lado para priorizar o treinamento de uma equipe do colégio.

Dos entrevistados, 75\% gostam da Educação Física, e entre esses, $83,3 \%$ apontaram o esporte como o que mais gostam de fazer nas aulas de Educação Física. Segundo Bracht (1997), Foucault diz que a escola é uma das instituições que submetem o corpo a procedimentos disciplinares, assim como fábricas e prisões. $\mathrm{O}$ autor também afirma que para Adorno a principal maneira de se disciplinar o corpo é a manipulação psíquica e esta pode ocorrer através da indústria cultural que tem como um de seus grandes "agentes" o esporte olímpico.

Em nosso trabalho, observamos que os alunos do treinamento desportivo entendem a Educação Física como "menos" importante do que o esporte, "porque pra mim a Educação Física é menos cobrada, do que o esporte mesmo. Educação Física não tem tanta exigência eu acho assim" (aluno/atleta 2); "Uai, no esporte escolar tem as regras né, e na educação física você joga mais sem as regras, só para tipo assim uma pelada" (aluno/atleta 4 ). 
Observamos nas respostas dos alunos que a Educação Física é considerada apenas sinônimo de esporte, porém "sem tanta exigência" ou "tipo assim uma pelada". Isto reforça a idéia de que a educação física ainda é trabalhada alicerçada em uma pedagogia tradicional, como se não houvesse nenhum conhecimento a ser assimilado, a não ser quando é o esporte para "competição". Os alunos apontam - além do jogo em si - apenas as regras como algo importante que deva ser aprendido por eles.

O professor da educação física não cobra praticamente nada das regras né, e quando você vai praticar a educação física tem muitos colegas que não sabe nem tem noção das regras de tipo assim igual nós estamos falando do futsal todo mundo já sabe né o professor cobra muito, então você tenta aprender o mais rápido possível pra não poder ficar pra trás dos colegas (aluno/atleta 4).

A influência do esporte se expressa nos objetivos dos alunos que participam dos jogos escolares. A maioria espera daquela prática uma carreira profissional. Vejamos alguns comentários:

"Pretendo começar a treinar na modalidade que eu gosto que é o futebol de campo; pretendo treinar pra entrar no ramo do futebol" (aluno/atleta 1); "Ah, eu queria ver se eu cresço no esporte mesmo, se eu conseguir ser um jogador, ou ser um professor de educação física, fazer alguma coisa na área do esporte, fisioterapeuta, preparador físico, quero investir no esporte mesmo" (aluno/atleta 2); "Uai, eu estava até conversando com um amigo meu, com nós ir fazer teste para seguir carreira jogando bola" (aluno/atleta 4).

Um dos alunos entende que já faz parte do universo do futebol profissional: "Ah... assim, crescer profissionalmente, eh... isso, [...] Eh... jogar num grande time e usar o que eu aprendi aqui, né?" (aluno/ atleta 3$)$.

Os alunos acreditam que podem seguir uma carreira profissional e ser como seus ídolos famosos, com muito dinheiro e o quanto antes possível: "o Jô [...], ele era do juvenil, imagina a fama que ele já tem" (relatório diário, de 17 de setembro de 2004). A idéia de que o futebol é para eles a maneira mais agradável e fácil de conseguir ser bem-sucedido na vida, ou melhor, enriquecer-se facilmente, é colocada a todo o momento na indústria cultural. Adorno e Horkheimer (1985, p. 136) dizem que a indústria cultural 
fixa para a espectadora, não apenas a possibilidade de também vir a se mostrar na tela, mas ainda mais enfaticamente a distância entre elas. Só uma pode tirar a sorte grande, só um pode ser célebre, e mesmo se todos têm a mesma probabilidade, esta é para cada um tão mínima que é melhor riscá-la de vez e regozijar-se com a felicidade do outro, que poderia ser ele próprio e que, no entanto, jamais é.

A indústria cultural cumpre seu papel de legitimar o sistema capitalista quando fixa para a sociedade a imagem de que qualquer jovem pode se tornar um profissional, pois as oportunidades são iguais para todos, basta treinarem e buscarem seus sonhos.

Quando um número muito grande de instâncias formadoras de consciência ideologicamente falsa age sobre uma mesma instituição, no caso o esporte, os agentes [no caso os praticantes] podem ser iludidos sobre seus próprios interesses verdadeiros (KUNZ, 2001, p. 27).

Um aspecto que nos chamou atenção foi a introdução da queimada nos jogos estudantis de Goiás nos mesmos moldes do esporte olímpico. Dunning, citado por Assis (2001, p. 86), sistematiza que "a orientação dominante do esporte moderno é constituída de três pilares: a crescente competitividade, a seriedade no modo de envolvimento e a orientação para os resultados".

Mesmo não sendo intenção dos organizadores, ${ }^{10}$ a esportivização da queimada, este jogo popular - da maneira como ele está sendo tratado atualmente - dentro dos JEEGO's assume elementos do esporte, e isto pode ser visto nos jogos assistidos.

Ambos os times utilizam de estratégia parecida, as jogadoras de fundo somente cruzam a bola para as colegas que estão dentro de quadra, para que estas tentem queimar as adversárias. O técnico de Itumbiara diz qual é a adversária que deve ser queimada. "Ambas as equipes participam do jogo cruzando e queimando somente duas jogadoras, quando outras pegam a bola passam para estas, ficando claro qual a função de cada uma" (Relatório diário, jogo queimada 2); "A jogadora de Morrinhos que 'queima' as adversárias é queimada e tem que ir para a reserva, então a outra jogadora que cruza as bolas vai para dentro da quadra, mas logo esta é queimada e volta para a reserva chorando" (Relatório diário, jogo queimada 1). 
Estas características fazem a queimada perder parte de seus aspectos culturais, pois em cada canto do país, ela é jogada de uma maneira, de acordo com a construção de cada local ou grupo. Pois, como afirma Carravetta (1997, p. 23), "o jogo é uma atividade livre, delimitada por um espaço e tempo preciso, fixado com antecedência, e regulamentada mediante a submissão de convenções".

Isto quer dizer que qualquer grupo faz suas regras no jogo; já no esporte isso não acontece porque as regras são definidas por uma instituição (Federações, Confederações etc.) e não podem ser mudadas por qualquer motivo. $\mathrm{O}$ esclarecimento sobre a diferença entre jogo e esporte deveria ser feito nas aulas de Educação Física, mas, como afirma Assis (2001, p. 16),

hoje, não só o esporte é o conteúdo exclusivo ou prioritário para a organização das aulas, como também outras formas culturais vão sendo esportivizadas através da realização de competições, da uniformização de regras etc.

Uma das características principais do esporte moderno é o secularismo. Para Stigger (2002, p. 20), “o esporte moderno é uma prática secular, ou seja, desvinculada de cerimônias ou festas religiosas, com as quais estavam relacionadas muitas outras atividades esportivas anteriores a ele".

No entanto, em todos os jogos vimos algum tipo de ritual religioso das equipes, a maioria rezando um "pai-nosso".

O árbitro apita então as equipes vão para suas orações, o Piracanjuba reza Pai Nosso, Ave Maria e um grito de "Jesus está comigo" (relatório diário 1); [...] após as instruções os jogadores e o treinador rezam um pai-nosso (Jogo futsal masculino, 2 de junho de 2004); [...] as duas equipes fazem orações e dão o grito de guerra (Jogo futsal masculino juvenil, 3 de junho de 2004); [...] depois de se alongarem, as equipes fazem suas orações e seus "gritos de guerra" (Jogo futsal feminino regional 2); [...] então não devem cair em nenhuma provocação, depois fizeram sua oração e foram para o jogo (Jogo de futsal feminino, 4 de junho de 2004).

Algumas equipes fizeram seu ritual também no final da partida, "O time do polivalente se reúne, todos se abraçam e formam um círcu- 
lo, o treinador fala com seus alunos depois fazem uma oração e um grito de guerra" (Jogo de futsal masculino, 4 de junho de 2004).

Chamamos a esta ação de ritual, pois, como Mair (1984, p. 219) afirma, o termo ritual é "usado como substantivo e significando um complexo de ações que envolvem inúmeras pessoas". As orações foram observadas em todos os jogos e envolveram todos os participantes de todas as equipes. Este fato torna-se interessante não só pelo esporte ser uma "prática secular", e como tal não ter nenhuma conotação religiosa, mas também porque a maioria das equipes surge de projetos de treinamento desportivo e os treinamentos, assim como o esporte, estão calcados em uma base científica, em que aparece outra característica do esporte, a racionalização.

Stigger (2002, p. 20) diz que

o esporte moderno é vinculado a uma racionalidade que estabelece relações entre meios e fins, o que se expressaria na criação e evolução de regras bastante explícitas e capazes de garantir alguma previsibilidade às competições, assim como na criação de tecnologias (equipamentos, métodos de treinamento etc.), que visam a alcançar determinados objetivos.

Aqui, observamos algo transmitido a todo momento na indústria cultural que é uma tentativa de "sacralização" do esporte e dos atletas, como se estes tivessem um "dom divino" e o esporte fosse um templo.

\section{CONSIDERAÇÕES FINAIS}

As entrevistas com os professores de Educação Física, Ciências e Ensino Religioso, com os alunos e as observações das aulas, dos treinamentos esportivos e dos jogos escolares nos possibilitaram um entendimento da forma como a educação do corpo se manifesta num dado ambiente escolar. Especificamente nas aulas de Educação Física observadas, percebemos dois pólos: de um lado o laissez-faire no trato com os conteúdos com e sem interferência limitada do professor; de outro, o treinamento com fim nos jogos escolares estaduais.

Identificamos, também, a padronização e enquadramento de um jogo, a queimada, nos moldes do esporte olímpico, transformando todo o seu potencial criativo e de cultura popular em um sistema rígido, fechado e controlado como é o modelo esportivo. 
A educação do corpo ainda está predominantemente sustentada na concepção biológica em que a disciplina Ciências ainda é sua única referência. A Educação Física contribui para o desenvolvimento do modelo esportivo, na reprodução dos valores desta prática ou através do diciplinamento via treinamento esportivo e competições em que o mais forte, mais ágil, mais rápido constitui-se como principal expressão.

A paródia do esporte olímpico parece ser uma expressão presente no esporte escolar, em que a reprodução do modelo esportivo através das suas competições e nos seus rituais aponta para uma forte influência da indústria cultural, determinando em muitos momentos o próprio esporte escolar.

A discriminação/preconceito com relação à cor da pele, condição social, forma corporal, desempenho físico, fealdade aparece no decorrer da pesquisa como forte indício de uma educação do corpo enraizada em modelos preestabelecidos e pouco flexível à diversidade da expressão do corpo da escola. A tematização dessas expressões pelas disciplinas estudadas, assim como pelo esporte escolar, inexistiu no decorrer da pesquisa, colocando esse ambiente educacional omisso a essas expressões tão marcantes na educação do corpo.

\title{
THE EDUCATION OF THE BODY IN EDUCATION ATMOSPHERES
}

\begin{abstract}
This work presents the main subjects originating from of a research that it aimed at to investigate, in compared perspective, the cares with the body and the corporal techniques in the children's school education and young, correlating aspects of contents and methodologies of the teaching of Physical education with the disciplines Sciences and Religious Teaching, as well as of the school sport and your presence in the classes of Physical education. The research was carried out a public school of Goiannia with students and teachers of the second phase of the Fundamental Teaching. We understood an education of the body in the school sustained in a biological conception, with valorization of the discipline of Sciences and strongly present in the school sport which maintains, through the sporting system, the manifestation model and expression in the school: through the competitions, of the formation of the idols, of the rationalization, of the training and of the development of their values. At the end, we understood the need to understand the education of the body of discipline form and of enlarging the focus of teaching of the sport in the school.
\end{abstract}

KEY-WORDS: education of the body - school - physical education - school sport 


\section{EDUCACIÓN DEL CUERPO EM AMBIENTES EDUCACIONALES}

\section{RESUMEN}

Este trabajo presenta las principales cuestiones originarias de una pesquisa con el objetivo de investigar, en perspectiva comparada, los cuidados con el cuerpo y las técnicas corporales en la educación escolar de niños y jóvenes, haciendo la correlación entre aspectos de contenidos y metodologías de la enseñanza de Educación Física con las asignaturas Ciencias Y Enseñanza Religiosa, así como del deporte escolar y su presencia a la clase de Educación Física. La pesquisa fue realizada en una escuela pública de la ciudad de Goiânia con alumnos y profesores de la segunda fase de la Enseñanza Fundamental. Percibimos una educación del cuerpo en la escuela sustentada por la concepción biológica, con valoración de la asignatura de ciencias fortemente presente en el deporte escolar lo cual mantiene a través del sistema deportivo el modelo de manifestación y expresión en la escuela: a través de las competiciones, de la formación de los ídolos, de la racionalización, del entrenamiento y del desarrollo de suyos valores. Al final, percibimos la necesidad de entender la educación del cuerpo de forma multidisciplinar y de ampliar el foco de enseñanza del deporte en la escuela.

PALABRAS-CLAVE: educación del cuerpo - escuela - educación física - deporte escolar

\section{NOTAS}

1 O presente trabalho é parte desse esforço e constitui as investigações desenvolvidas nos anos 2003 e 2004 pelo grupo da Faculdade de Educação Física-UFG de Goiânia. Posteriormente, iremos analisar numa perspectiva comparada com os outros campos de pesquisa.

2 A carga horária desta disciplina é de três aulas semanais por turma.

3 A carga horária desta disciplina é de uma aula semanal por turma.

4 Estas questões estão bastante presentes nas entrevistas realizadas com as professoras de Educação Física, as quais afirmam que a Educação Física não tem valor dentro da escola e é menosprezada em relação às demais disciplinas.

5 Para Mauss (1974, p. 211), técnicas corporais são "as maneiras como os homens, sociedade por sociedade e de maneira tradicional, sabem servir-se de seus corpos".

6 As técnicas disciplinares relacionadas à arquitetura da escola pesquisada são caracterizadas pela sua similaridade com uma prisão, em que se tem muros com cacos de vidro, vários portões com grades 
e que geralmente, mesmo durante a ocorrência de aulas, ficam trancados com cadeado.

7 Este tipo de estudo relaciona-se à prevenção de Doenças Sexualmente Transmissíveis, à gravidez e ao conhecimento dos órgãos sexuais.

8 Atualmente, a busca pelo "corpo ideal" está intimamente subjugada ao avanço da ciência e da tecnologia. Deste modo, a incessante busca da beleza encontra na interferência cirúrgica, na utilização de processos químicos, entre outros processos artificiais, o melhor caminho para o alcance de tal objetivo. Neste processo, o conhecimento, ou seja, a razão aparece com predominância em relação à natureza humana, uma vez que o corpo torna-se capital rentável impulsionado pelo consumo.

9 Entendemos que a queimada é um jogo popular, no entanto, com a introdução desta atividade nos jogos escolares, ela assume todas as características do esporte (padronização, quantificação, competição) e é neste jogo que a escola pesquisada se destaca em nível estadual.

10 Em entrevista com o gerente desportivo, ele nos afirmou que a queimada está nos JEEGO's há dois anos, por ser uma reivindicação dos professores e pela grande quantidade de alunos que a pratica nas escolas. Também diz ter ciência de alguns "problemas" nesta modalidade e que ao final dos jogos são feitos relatórios, os quais são usados para discussões de possíveis mudanças nos JEEGO's.

\section{REFERÊNCIAS}

ADORNO, T. W.; HORKHEIMER, M. Dialética do Esclarecimento. Rio de Janeiro: Jorge Zahar, 1985.

ASSIS, S. Reinventando o esporte: possibilidades da prática pedagógica. Campinas: Autores Associados, 2001.

BRACHT, V. Sociologia crítica do esporte: uma introdução. Vitória: CEFD-UFES, 1997.

- A constituição das teorias pedagógicas da educação física. In: SOARES, C. L. (Org.). Cadernos Cedes, Campinas, ano 19, v. 19, n. 48, p. 69-88, ago. 1999.

CARraVetTA, E. S. O esporte olímpico. Porto Alegre: Universidade/UFRGS, 1997. 
CODO, W.; SENNE, W. A. O que é corpo(latria). São Paulo: Brasiliense, 1985.

FRAGA, A. B. Anatomias emergentes e o bug muscular: pedagogias do corpo no limiar do século XXI. In: SOARES, C. L. (Org.). Corpo e História. Campinas: Autores Associados, 2001. p. 61-77.

KUNZ, E. Transformação didático-pedagógica do esporte. Ijuí: Unijuí, 2001.

MAIR, L. Introdução à antropologia social. Rio de Janeiro: Zahar Editores, 1984.

MAUSS, M. As técnicas corporais. In: MAUSS, M. Sociologia e antropologia. São Paulo: EPU, 1974. p. 209-233.

SILVA, A. M. Corpo, ciência e mercado: reflexões acerca da gestação de um novo arquétipo da felicidade. Campinas: Autores Associados/ UFSC, 2001.

STIGGER, M. P. Esporte, lazer e estilos de vida: um estudo etnográfico. Campinas: Autores Associados, 2002.

VAZ, A. F. Treinar o corpo, dominar a natureza: notas para uma análise do esporte com base no treinamento corporal. In: SOARES, C. L. (Org.). Cadernos Cedes, Campinas, ano 19, v. 19, n. 48, p. 89-108, ago. 1999.

. Ensino e formação de professores e professoras no campo das práticas corporais. In: VAZ et al. (Org.). Educação do corpo e formação de professores: reflexões sobre a prática de ensino de educação física. Florianópolis: UFSC, 2002.

WERNECK, C. L. G. Educação Física: novos olhares sobre o corpo. In: SOUZA, E. S. de; VAGO, T. M. (Orgs.). Trilhas e partilhas: educação física na cultura escolar e nas práticas sociais. Belo Horizonte: Cultura, 1997. p. 299-326. 
Recebido: 31/03/2005

Aprovado: 01/06/2005

Endereço para correspondência:

Ari Lazzarotti Filho

Rua T-60 n. 31 Ap. 207 - Setor Bueno

Goiânia - GO

CEP 74223-160

E-mail: guego@fef.ufg.br 
